\title{
Enterprise Systems Education through Supply Chain Management
}

\author{
David Ang \\ Auburn University Montgomery \\ E-Mail: dang@aum.edu \\ Tom Griffin \\ Auburn University Montgomery \\ E-Mail: tgriffin@aum.edu \\ Jane Goodson \\ Auburn University Montgomery \\ E-Mail: jgoodson@aum.edu \\ Johnny Ho \\ Columbus State University \\ E-Mail: ho_johnny@colstate.edu
}

\begin{abstract}
The U.S. and other developed nations are experiencing competitiveness in offering higher educational degree programs. Due to the rise of more private and online educational institutions, existing traditional class room teaching institutions are facing the impact of intensifying competition in recruitment and graduation. This created the so-called "Enterprise Systems Education” at large. Many strategies are designed and developed internally to attain competitiveness. One should consider adopting the systems concept of close collaboration and integration efforts with the industries which the commercial enterprises have deployed successfully for decades to attain competitiveness. This paper describes the use of Supply Chain Management (SCM) principles as an effective strategy to attain competitiveness for these so-called "Enterprise Systems Education” institutions.
\end{abstract}

Keywords: Supply Chain Management Competitiveness Enterprise Systems 


\section{ENTERPRISE SYSTEMS EDUCATION THROUGH SUPPLY CHAIN MANAGEMENT}

The definition of "enterprise” can be defined as sharing a set of common goals by assemblage organizations. Current practices at the higher learning institution in U.S. are examples of enterprises. Higher learning institutions share the common goals working toward achieving competitiveness in increasing enrollment and improving graduation. Due to the arise of more private institutions and online degree programs offered, existing traditional class room teaching universities, public or private are facing the impact of intensifying competition. These days, managers from the industry are concerned that it takes too long to train graduates with job skills and subject knowledge required to perform in workplace. From the perspective of employers, increasing the enrollment and graduates is not sufficient. It is the ability to match the customer's requirements that is important to employers. Matching these requirements constitutes an entirely new type of educational challenge for the higher learning institutions.

The employers are the end users or customers who demanded qualified graduates with the expected job skills and knowledge to perform at workplace when hired. On the other hand, the higher learning institutions are the suppliers who are expected to produce these qualified graduates for the industries. A supplier and customer relationship exists between the higher learning institutions and the employers. Eventually, this relationship can be further expanded to include other functional departments within the university systems to form a network of close collaboration and integration to work toward producing qualified graduates for the employers. The Supply Chain Management (SCM) principle has been considered as the most effective operations strategy to gain organizational competitiveness through the network of close collaboration and integration in term of demand and supply. The purpose of this paper is to provide a framework to describe the use of Supply Chain Management (SCM) principles as an effective strategy to attain competitiveness for these so-called "Enterprise Systems Education" institutions. The framework focuses only on strategies and tactics, not on operational issue.

\section{LITERATURE REVIEW}

Researchers such as Gunnarsson and Jonsson (2003), (Gunasekaran, 2004), and Themistocleous, M. et al. (2004) described SCM as a network of relationships and connections between partners like suppliers and customers. It is also regarded as an integrated management from designing product to development, business links, 
information flows, and people (Themistocleous, et al. 2004). SCM aims to achieve business competitive advantages through the coordination of resources and the optimization of activities across the supply chain. Its coordination and optimization activities include planning supply and demand, managing operations and information, sourcing materials and components, running productions, tracking quality and inventories, and delivering to end users and customers (Chow et al., 2008). Achieving organizational competitiveness depends upon how effectively SCM is implemented. An effective SCM can result in organizational competitiveness in productivity gain, product quality, greater operational efficiencies, lower operational costs, faster products delivery to market, profitable growth, and higher customer satisfaction.

Gunasekaran et al. (2008) stated these functional activities include (1) procurement (maximum purchasing discounts), (2) inbound logistics (low transportation cost), (3) operations (low production costs), (4) marketing and sales (wide product range/high availability), and (5) outbound logistics (low transportation costs) are needed to achieve competitiveness through responsive supply chain. Chow et al. (2008) identified that the effectiveness of practicing SCM can be structurally or situation-dependent on different cultural environments. Lambert et al. (2005) noted the three major elements needed to implement supply chain are the supply chain processes, network structure, and management components. Gunasekaran and Ngai (2004) addressed the disadvantages and difficulties to streamline operations without effective IT systems to provide information for making the best supply chain decisions.

As stated by Themisocleous et al. (2004), D’Amours, S., et al. (1999), and Thonemann, U.W. (2002), an effective SCM which can be achieved through successful integration of business processes and information flows of the partners within the supply chain. Themistocleous et al. (2004) acknowledged there is no single integration technology available to overcome all obstacles embedded in the integration process. They suggested overcoming the integration process through the concept of multiple permutations integration.

Many papers and articles discussed on the strategies, techniques and technologies, and the taxonomy of SCM design and modeling such as (Tan, 2001) were found. However, no literatures or articles discuss the application of SCM principles in higher learning institutions or educational systems. 


\section{SCM: A STRATEGY FOR HIGHER LEARNING INSTITUTION}

SCM is a principle emphasizing the utilization of an efficient integrated system of suppliers, producers, customers, buffers, informational flow, and logistic distribution, so that items can be produced and distributed system-wide at the right quantities, locations, and time to minimize costs and maximize services. Supply chain activities can cover everything from designing to product development, sourcing, manufacturing, marketing, logistics, and information systems needed to coordinate these activities.

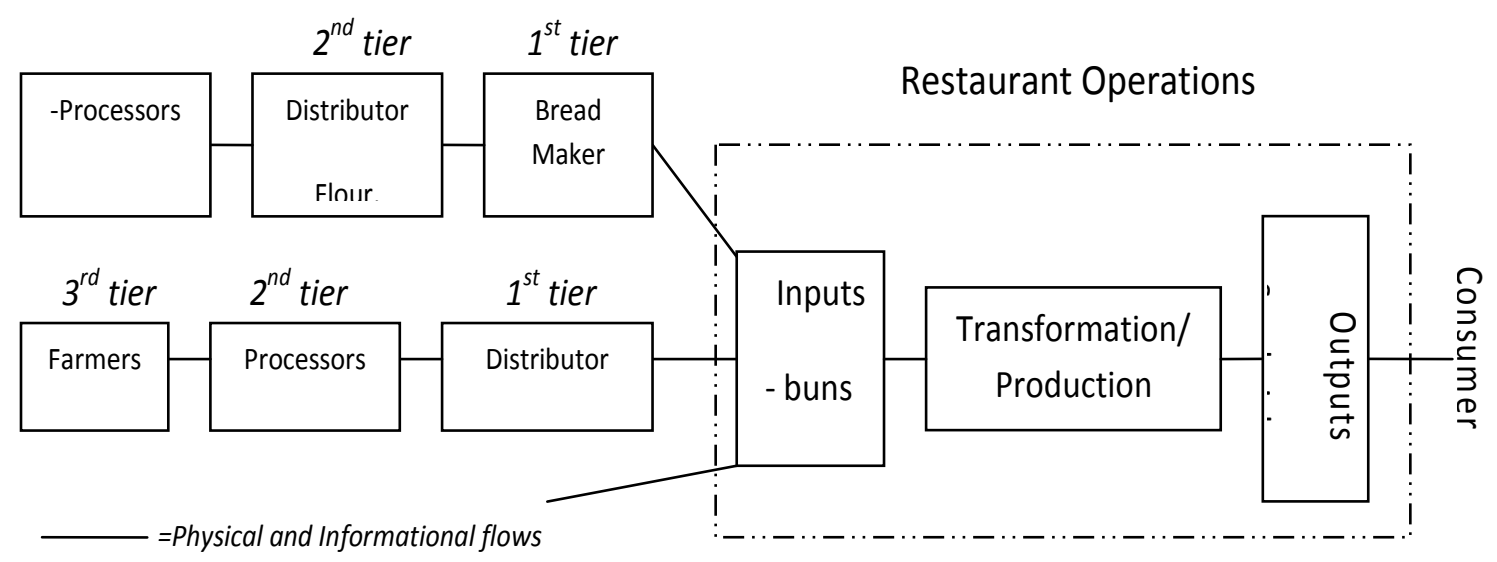

Figure 1 Simplified Supply Chain of a Restaurant

Consider a restaurant that serves sandwiches (see Figure 1). Customers probably won't even realize that the range of activities involve in transforming can be overwhelming before the sandwich is ready to be purchased. The members within the supply chain play the roles as suppliers, customers, and even as team with conscious collaboration and integration coordination. If the Restaurant in Figure 1 is disjointed from the supply chain, the restaurant mainly will plan, lead, organize, and control its transformation process internally by itself with its own perception of value. This value could be attained even well in quality, price, speed, and accuracy of delivery if and only if upstream members can act systematically as partners to create value at every stage of the supply chain.

In this paper, the framework of the higher learning educational supply chain systems is designed and described in Figure 2. The figure characterizes the industries, schools, colleges, or program departments as customers, suppliers, and producers that 
can be chained together to form an educational supply chain systems. For instance, the customers are the focal industries and the suppliers and producers are the respective school, college, and inter-departmental unit within the university setting. A critical step in implementing the SCM is to be able to recognize the major elements that constitute the SCM principles. These principle elements are 1) Customers (requirements), 2) Purchasing (sourcing), 3) the Operations Management (i.e. Design, Process selections, forecasting, logistics, Inventory management, scheduling, etc.) activities to transform inputs to outputs, and 4) partner relationships network management. As depicted in Figure 2, the implementation should begin with the focal industries to address the graduates' qualifications to their upstream suppliers such as the respective school and college within the university. The industries should clearly define the specific job skills and knowledge requirements as needed for the graduate to be able to perform at their workplace when hired. The Tier 1 upstream suppliers such as the respective school and college assimilate the industries' requirements by transcribing them into effective courses with required learning goals in their program curriculum. Students can then be educated with the job skills and knowledge by taking a series of rigorous courses in their program of study. When students graduated they should termed to be qualified and can be hired to work for employers effectively with little further trainings.

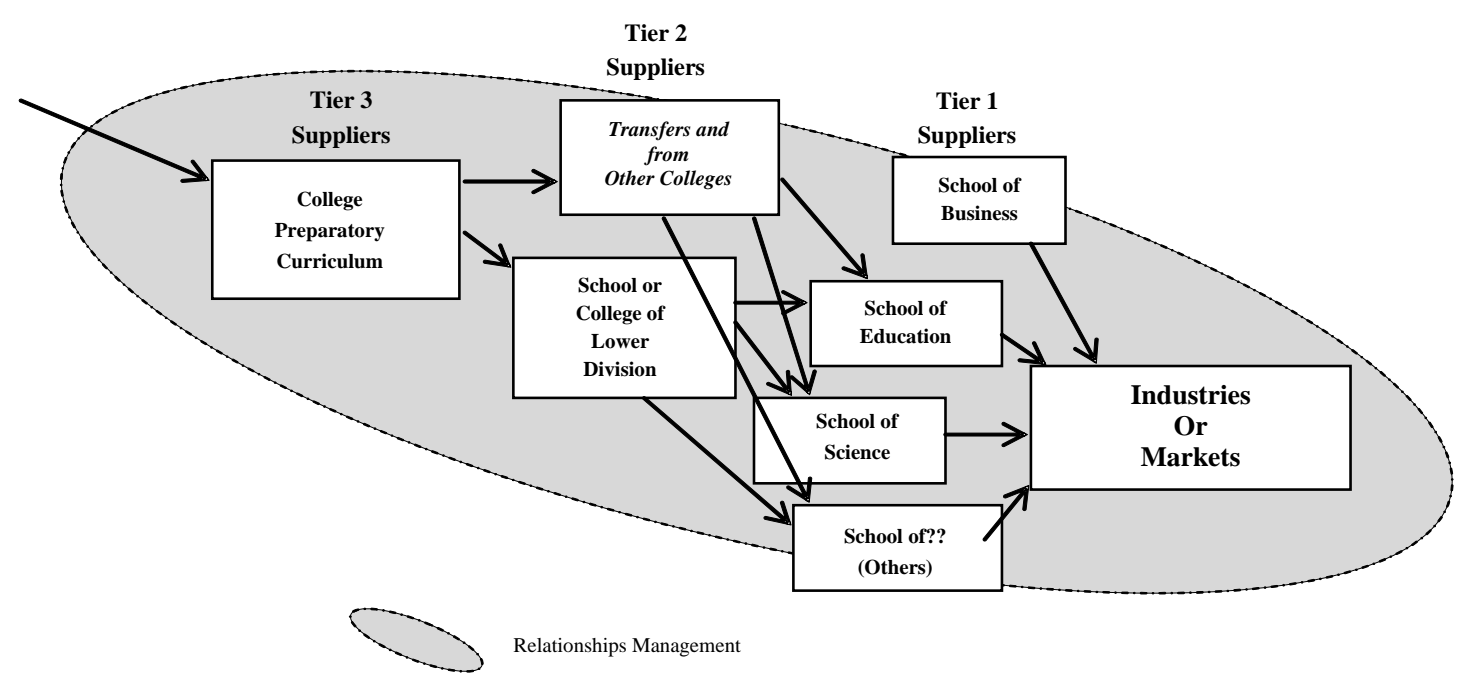

Figure 2 Framework of Higher Learning Educational Systems Supply Chain 
The respective school and college termed as the Tier 1 supplier will now assume the role as downstream producer. Tier 1 producer will need to work with its upstream suppliers to initiate and mandate its suppliers, the Tier 2, to provide their supply requirements. In this scenario, Tier 1 producer would request its supplier with the supply requirements and specifications such as the students' qualifications, grade points averages, prerequisites, and others. This initiative signals the use of the pullbased rather than the push-based supply chain demand strategy. The pull-based strategy simply means that the demand is always initiated from the downstream users or producers and the upstream suppliers will always assimilate the requirement specifications from their downstream producers. Essentially, as shown in the Figure 2, the entire supply chain is a series of customers' customers and suppliers' suppliers. Thus, relationship management systems must also be developed to oversight the collaboration and integration activities based on the given level of demand and supply along the supply chain. This relationship management system is also needed to coordinate the information and material flows among the supply chain members in the supply chain. If this educational supply chain management system is implemented well, qualified graduates with exemplary education and career pathways can be achieved.

\section{Steps in Creating Higher Learning SCM}

Creation of an effective supply chain as depicted in the framework of Figure 2 entails several key strategic issues and tactics:

1. Identify and understand the terminal learning goals requirement (job skills and knowledge) of the industries through industry-education partnership and liaisons.

2. Develop a decision support system or team to oversight the selection of suitable suppliers and producers (department, program, courses, learning goals, etc) according to their core competencies, the design of the programs delivery (learning goals), and the performance measurement of each stage along the supply chain to ensure process integrity and quality.

3. Coordinate planning to execute information (learning goals) and materials (students) across the supply chain. This requires a system for transferring and sharing common database of students records such as grade, background courses, decision delegation authority, data on performance measurement that are pertinent to the decision making process or continuous improvement process along the supply chain. 


\section{CONCLUSIONS}

In this paper the framework of using SCM as an effective strategy to achieve competitiveness in higher learning educational systems is discussed. The framework only discussed the strategies and tactics, not on operational issue. The competitiveness can be achieved if student's terminal learning goals can align with the job skills and knowledge requirements to perform at workplace. When graduates are able to perform, industries and organizations in the society will be satisfied. Higher learning institutions that produced them should gain better reputation in term of their program quality and integrity. Enrollments may also be increased due to the fine perceptions and the demands of their graduates in the industries.

Since higher learning educational system is a service provider sector, supply chains for services are sometimes not as easily defined as supply chain for manufacturing sectors. There are several key issues to recognize the differences in SCM applications between the two sectors. Service sector supply chain focuses more on human resources and support services since it does not always provide customer or downstream producer with a physical good. Service sector supply chain tends to be more compact than the manufacturing sector because service sector does not have many suppliers and tiers. Since it does not have many supplier and tiers, the service sector logistics distribution network for material and physical good flows may or may not exist in the supply chain. Regardless, as described in this paper, service sector supply chain is definable and business benefits and competitiveness can be effectively achieved through the implementation of SCM.

\section{REFERENCES}

D'Amours, S., Montreuil, B., Lefrancois, P., \& Soumis, F. (1999). Networked manufacturing: The impact of information sharing. International Journal of Production Economics, 58(1), 63-79.

Gunasekaran, A. (2004). Supply chain management: Theory and applications. European Journal of Operational Research, 159(2), 265-268.

Gunasekaran, A., Lai, Kee-hung, \& Cheng, T.C. Edwin (2008). Responsive supply chain: A competitive strategy in a networked economy. Omega, 36(4), 549 -564.

Gunnarsson, G., and Jonsson, S. (2003). Charge the relationships and gain loyalty effects: Turning the supply link alert to IT opportunities. European Journal of Operational Research, 144, 257-269.

Lambert, D. M., Garcia-Dastugue S., \& Croxton K. L. (2005). An evaluation of process-oriented supply chain management frameworks. Journal of Business Logistics, 26(1), 25-57. 
Tan, K.C. (2001). A framework of supply chain management literature. European Journal of Purchasing \& Supply Management, 7, 39-48.

Themistocleous, M., Irani, Z., and Love, Peter (2004). Evaluating the integration of supply chain information systems: A case study. European Journal of Operational Research, 159(2), 393-405.

Thonemann, U.W. (2002). Production, manufacturing and logistics improving supplychain performance by sharing advance demand information. European Journal of Operational Research, 142(1), 81-107.

Chow, Wing S., Christian N. Madu, Chu-Hua Kuei, Min H. Lu, Chinho Lin and Hojung Tseng (2008). Supply chain management in the US and Taiwan: An empirical study. Omega, 36(5), 665-679. 